PDFlib PLOP: PDF Linearization, Optimization, Protection

Page inserted by evaluation version www.pdflib.com - sales@pdflib.com 


\section{NE Hatch}

\section{Author's affiliation:}

Nan E. Hatch, Department of Orthodontics and Pediatric Dentistry, School of Dentistry, University of Michigan, Ann Arbor, MI, USA

\section{Correspondence to:}

Nan Hatch

Department of Orthodontics and Pediatric Dentistry

School of Dentistry

University of Michigan

1011 N University Avenue

Ann Arbor

MI 48109 1078, USA

E-mail:nhatch@umich.edu

Dates:

Accepted 29 January 2007

To cite this article:

Hatch NE:

Potential role of PC-1 expression and pyrophosphate elaboration in the molecular etiology of the FGFR-associated craniosynostosis syndromes

Orthod Craniofacial Res 10, 2007; 53-58

Copyright $\odot 2007$ The Author.

Journal compilation @ 2007 Blackwell Munksgaard

\section{Potential role of PC-1 expression and pyrophosphate elaboration in the molecular etiology of the FGFR- associated craniosynostosis syndromes}

\begin{abstract}
Structured Abstract
Author - Hatch NE

Background - Fibroblast growth factor/fibroblast growth factor receptor (FGF/FGFR) signaling is associated with the aberrant mineralization phenotype of the craniosynostosis syndromes. One critical aspect of mineralization involves the elaboration and transport of pyrophosphate into the extracellular matrix with subsequent enzymatic hydrolysis into phosphate. We have previously shown that FGF2 up-regulates expression of the pyrophosphate generating enzyme, PC-1, and the pyrophosphate channel, ANK, while down-regulating expression of the pyrophosphate hydrolyzing enzyme, tissue non-specific alkaline phosphatase in preosteoblastic, MC3T3E1(C4) cells. These results suggest that FGF/FGFR signaling may affect mineralization via changes in the elaboration and metabolism of pyrophosphate.

Objectives - We are currently conducting experiments towards a more systematic analysis of PC-1 expression in osteoblastic cells, in order to more clearly elucidate the significance of pyrophosphate elaboration in the process of normal bone mineralization and in the molecular etiology of the FGFR-associated craniosynostosis syndromes.
\end{abstract}

Design - Towards this goal we have constructed a PC-1 gene promoter/firefly luciferase reporter construct, in order to more directly investigate the regulation of PC-1 by FGF/FGFR signaling in osteoblastic and non-osteoblastic cells.

Results and Conclusions - Preliminary results confirm that FGF/FGFR signaling, either via treatment with FGF2 or via expression of a Crouzon syndrome-associated mutant FGFR2, induces PC-1 promoter activity in osteoblastic cells in culture. This appears to be a cell type specific phenomenon. These results suggest that the expression of PC-1 downstream of FGF signaling is an integral aspect of osteoblastic function, and that pyrophosphate elaboration may play a significant role in the pathology of craniosynostosis.

Key words: craniosynostosis; fibroblast growth factor; mineralization; osteoblast; PC-1; pyrophosphate

\section{Introduction}

Mutations in fibroblast growth factor receptors have been associated with a series of human malformation disorders known as the craniosynostosis 
syndromes. These clinical syndromes typically involve the premature fusion of specific cranial sutures (craniosynostosis) with a resultant characteristic skull shape, midface deficiency, hypertelorism, and proptosis. Clinical diagnosis of a given syndrome is also often based upon the existence (or lack thereof) of associated limb abnormalities such as syndactyly. It is commonly accepted that syndromic craniosynostosis can result from aberrant mineralization downstream of overactive fibroblast growth factor/fibroblast growth factor receptor (FGF/FGFR) signaling in the cranial suture environment, yet the mechanism by which FGF signaling elicits this phenotype has yet to be fully elucidated (1-3). It is possible to imagine FGF/FGFR signaling controlling cranial suture development and fusion via several distinct mechanisms. FGF/FGFR signaling could control pre-osteoblast/osteoblast recruitment, differentiation, proliferation and/or apoptosis. Unfortunately, studies that have attempted to link expression of craniosynostosis mutant FGFRs with these types of changes in cellular phenotype have revealed conflicting and inconsistent results (4-11).

Pyrophosphate is a well-established inhibitor of mineralization, yet when hydrolyzed by tissue nonspecific alkaline phosphatase (TNAP) into phosphate, it becomes a substrate for mineralization $(12,13)$. PC-1, ANK and TNAP are three factors that regulate pyrophosphate elaboration by osteoblastic cells, via its generation, transport and hydrolysis. Altered expression of these three factors downstream of FGF/FGFR signaling could provide a potential mechanism for the aberrant mineralization phenotype of the FGFR-associated craniosynostosis syndromes (Fig. 1).

PC-1 is a nucleoside triphosphate pyrophosphohydrolase (NTPPPH) that generates pyrophosphate from the catalysis of ATP (14). The influence of PC-1 activity on calcification of tissues is complex. PC-1 activity increases both intracellular and extracellular levels of pyrophosphate, a known inhibitor of hydroxyapapatite crystal propagation $(15,16)$. Yet pyrophosphate can also function as a source of phosphate for crystal generation when it is hydrolyzed by the more mature osteoblastic enzyme, TNAP (17). The superficially paradoxical role of PC-1 in tissue calcification is evidenced by the fact that PC-1 null mice exhibit diminished physiologic bone mineralization but dramatically increased pathologic calcification of normally unmineralized tissues (18). This finding, plus the

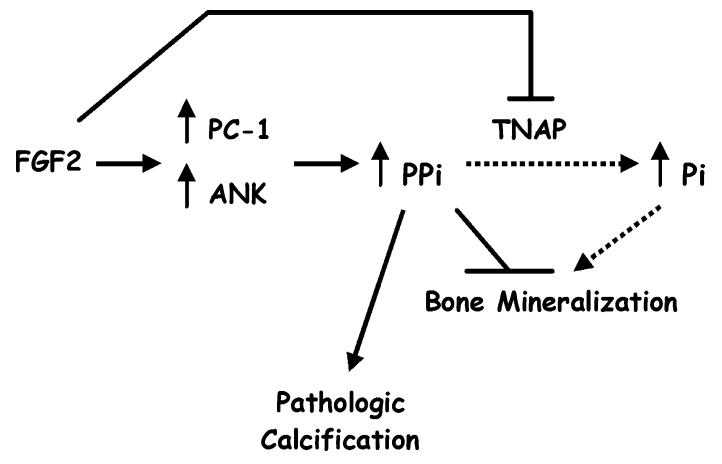

Fig. 1. Fibroblast growth factor 2 (FGF2) regulates the elaboration and hydrolysis of pyrophosphate in MC3T3E1(C4) cells. FGF2 induces PC-1 and ANK expression, which increases levels of extracellular pyrophosphate. FGF2 inhibits expression of tissue non-specific alkaline phosphatase, which prevents catalysis of pyrophosphate into phosphate. Increased levels of pyrophosphate and diminished levels of phosphate inhibit mineralization while diminished levels of pyrophosphate and increased levels of phosphate enhance mineralization. Excessive pyrophosphate levels can also result in ectopic calcification. Solid black lines indicate FGF-induced pathways; dashed lines indicate other potential pathways.

fact that PC-1 has been shown to be up-regulated during calvarial osteoblast differentiation in culture, supports the idea that while pyrophosphate is itself an inhibitor of mineralization, pyrophosphate can also act as a critical source of phosphate for bone mineralization (16). Significantly, a cross of the TNAP-/- mouse with the PC-1-/- mouse generates a double knockout mouse with apparently normal calvarial bone mineralization (19). This result clearly supports the idea that PC-1 and TNAP work in balanced concert to produce normally mineralized bone matrix via the elaboration and hydrolysis of pyrophosphate.

ANK is a 12 membrane spanning protein that has been linked to two separate human diseases of mineralization (chondrocalcinosis and craniometaphyseal dysplasia) (20-22). ANK expression and activity results in decreased levels of intracellular pyrophosphate and increased levels of extracellular pyrophosphate (23).This function of ANK is blocked by treatment with probenicid (an anion channel inhibitor) which suggests that ANK functions in the cell membrane as a channel for the transport of pyrophosphate from the intra to the extracellular space (23). ANK has been shown to be expressed in cartilaginous tissues as well as in developing endochondral and intramembraneous bone (24). The critical role of ANK in the calcification of tissues is evidenced by the fact that inactivating mutations in ANK result in a phenotype that is similar to the PC-1 knockout mice in terms of pathologic calcification (18). 
Altered expression of pyrophosphate/phosphate elaborating factors downstream of FGF/FGFR signaling could provide a potential mechanism for the changes in mineralization seen in FGF2 treated and FGF2 transgenic mice, as well as for the aberrant mineralization phenotype of the mutant FGFR-associated craniosynostosis syndromes. $\mathrm{PC}-1$ is the primary enzymatic generator of pyrophosphate in osteoblastic cells (17), therefore, the induction of PC-1 by FGF2 may be a primary mechanism by which FGF2 effects mineralization by osteoblastic cells. FGF2 treatment up-regulates expression of PC-1 and ANK while downregulating expression of TNAP in MC3T3E1(C4) cells (25; Fig. 2). This result is consistent with the finding that continuous FGF2 treatment inhibits mineralization in vitro, in that increased expression of PC-1 and ANK, combined with diminished expression of TNAP, will increase extracellular levels of pyrophosphate. Our findings suggest that FGF signaling has a direct bone
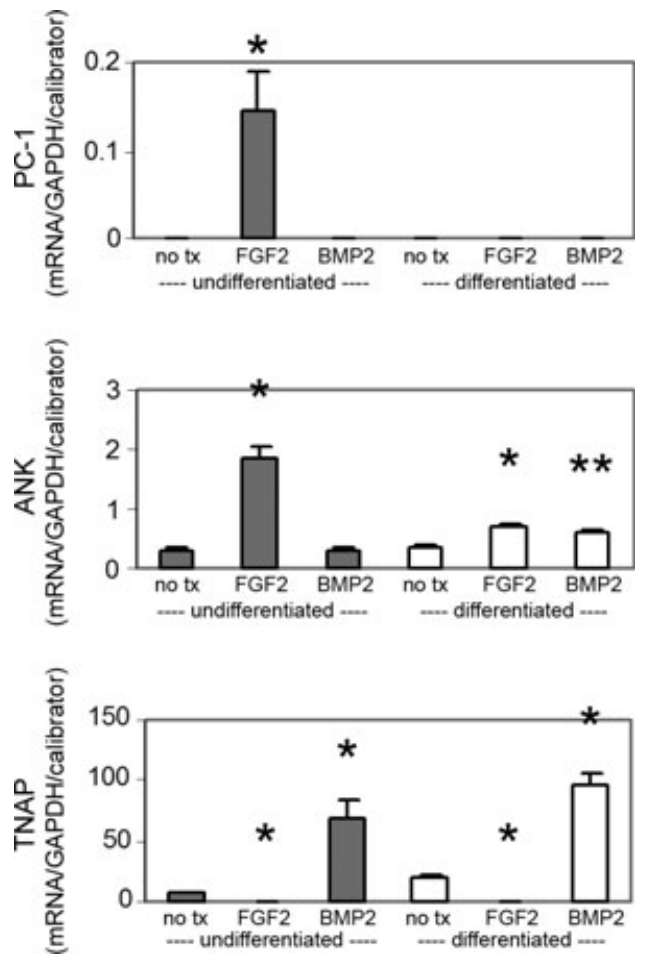

Fig. 2. Fibroblast growth factor 2 (FGF2) regulates mRNA expression of PC-1, ANK and tissue non-specific alkaline phosphatase in MC3T3E1(C4) cells. Undifferentiated MC3T3E1(C4) cells were cultured in $\alpha \mathrm{MEM} / \mathrm{ITS} \pm 50 \mathrm{ng} / \mathrm{ml} \mathrm{FGF} 2$, or $100 \mathrm{ng} / \mathrm{ml} \mathrm{BMP} 4$ for $48 \mathrm{~h}$. Differentiated MC3T3E1(C4) cells were cultured in $\alpha \mathrm{MEM} / 10 \%$ FBS containing $100 \mu \mathrm{g} / \mathrm{ml}$ ascorbate for 5 days and then cultured in $\alpha \mathrm{MEM} / \mathrm{ITS} \pm 50 \mathrm{ng} / \mathrm{ml} \mathrm{FGF} 2$, or $100 \mathrm{ng} / \mathrm{ml}$ BMP4 for $48 \mathrm{~h}$. RNA was isolated and utilized for real-time PCR. Results shown are mean \pm SD of pooled data from three separate experiments. Dark gray bars indicate undifferentiated cells; white bars indicate differentiated cells. ${ }^{*} p<0.01$ vs. no tx; ${ }^{* *} p<0.05$ vs. no tx. mineralization inhibitory effect on calvarial preosteoblastic cells that is provided, at least in part, through the elaboration of pyrophosphate via increased expression of PC-1. Additionally, when closely compared with the phenotype of mutant FGFR-associated craniosynostosis syndromes, our results suggest the possibility that craniosynostosis occurs as a result of excessive levels of extracellular pyrophosphate.

The primary objective of this study was to establish a system for more intensive investigation into the role of PC-1 in osteoblast mineralization and calcification. Initial results with this system suggest that the induction of PC-1 by FGF2 is cell type specific, and that expression of a craniosynostosis syndrome-associated mutant FGFR (FGFR2 $^{\mathrm{C} 278 \mathrm{~F}}$ ) does induce PC-1 in osteoblastic cells.

\section{Materials and methods}

Cell culture

The MC3T3E1(C4) murine osteo-progenitor cell line was purchased from American Type Culture Collection. MC3T3E1(C4) cells have been shown to exhibit high osteoblastic differentiation potential upon addition of ascorbate and were utilized to investigate effects of FGF signaling in pre-osteoblastic cells and osteoblastic cells $(26,27)$. To maintain cells in an undifferentiated state, cells were cultured in custom formulated $\alpha$ MEM containing no ascorbate supplemented with $10 \%$ FBS and penicillin/streptomycin. To induce differentiation, cells were cultured in $\alpha \mathrm{MEM}$ supplemented with $100 \mu \mathrm{g} / \mathrm{ml}$ ascorbate (Sigma, St. Louis, MO, USA), 10\% FBS and penicillin/streptomycin. COS7 cells are a commonly utilized kidney cell line and were used here to investigate effects of FGF2 signaling in non-osteoblastic cells. COS7 cells were cultured in DMEM supplemented with $10 \%$ FBS and penicillin/streptomycin. For all experiments, cells were plated at $10^{6}$ cells $/ 10 \mathrm{~cm}^{2}$ plate or 300000 cells per 6 well, and grown at $37^{\circ} \mathrm{C}, 5 \% \mathrm{CO}_{2}$.

Superfect transfection reagent (Qiagen, Valencia, CA, USA) was utilized for all transfection experiments, following manufacturer's recommended protocol. Briefly, cells were incubated with DNA/Superfect complexes for 4 hours, in media containing $10 \%$ FBS and penicillin/streptomycin. Cells were then washed with phosphate-buffered saline and media was replaced. Cells were incubated for an additional $24 \mathrm{~h}$ prior to cytokine treatment and/or cell lysis. 


\section{DNA constructs}

A 2864-bp region of the proximal PC-1 gene promoter was cloned by PCR utilizing the primers $5^{\prime}$-AGAGCGGGACGATGGAGCGCGA-3' and 3'-CCTACCAGCGACAGCACTTTGTAGGTGT-5'. This PCR product was digested with the restriction enzymes, Kpn1 and Xhol, purified and ligated into Kpn1, Xho I cut and purified PGL3basic vector (Promega, Madison, WI, USA), to create the PGL3/PC1-luc gene promoter/reporter construct. The translation initiation start site of the PC-1 promoter was subsequently eliminated via in vitro mutagenesis utilizing the 'QuickChange Site Directed Mutagenesis Kit' (Stratagene, La Jolla, CA, USA).

\section{Cytokine and inhibitor treatments}

All cytokine treatments were conducted in media containing $0.5 \%$ FBS and penicillin/streptomycin. Human recombinant FGF2 (Peprotech, Rocky Hill, NJ, USA) was added to a final concentration of $50 \mathrm{ng} / \mathrm{ml}$ along with $1 \mu \mathrm{g} / \mathrm{ml}$ heparin (Sigma). Human recombinant BMP2 (R\&D Systems, Minneapolis, MN, USA) was added to a final concentration of $100 \mathrm{ng} / \mathrm{ml}$. Cells were incubated with indicated cytokine for $24 \mathrm{~h}$ prior to mRNA isolation or cell lysis for luciferase activity.

\section{Luciferase assays}

Luciferase expression in whole cell lysates was assayed using the Firefly Luciferase Assay System (Promega) and a moonlight 2010 luminometer (Analytical Luminescence Laboratory, San Diego, CA, USA), following manufacturer protocol. Briefly, cells were scraped into $1 \times$ Passive Lysis Buffer, vortexed for $15 \mathrm{~s}$ (Promega) and centrifuged at $\mathrm{g}=36,149$ for $10 \mathrm{~min}$ at $4^{\circ} \mathrm{C}$. Supernatants were transferred to fresh eppendorf tubes on ice and stored at $-80^{\circ} \mathrm{C}$ until use. Twenty-microliter aliquots of cell lysate were combined with $100 \mu \mathrm{l}$ of Firefly Luciferase Reagent (Promega) for luciferase activity counts.

\section{Results}

FGF2 induces PC-1 promoter activity in MC3T3E1(C4) cells

In order to more directly study the mechanism by which FGF/FGFR signaling induces PC-1 expression,

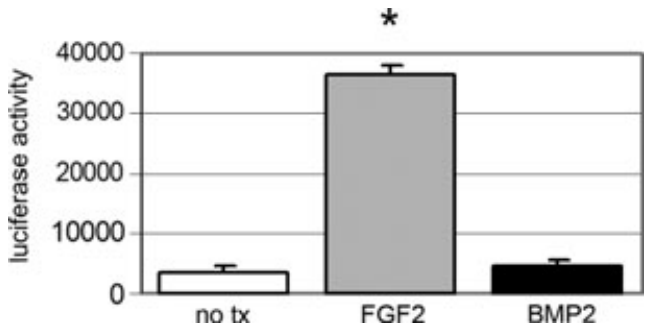

Fig. 3. Fibroblast growth factor 2 (FGF2) induces PC-1 promoter activity in undifferentiated, pre-osteoblastic MC3T3E1(C4) cells. MC3T3E1(C4) cells were transfected with a PC-1 gene promoter/ firefly luciferase construct (PGL3/PC1-luc), washed and incubated for $24 \mathrm{~h}$. Cells were then treated with $50 \mathrm{ng} / \mathrm{ml}$ recombinant FGF2 or $100 \mathrm{ng} / \mathrm{ml}$ BMP2 for an additional $24 \mathrm{~h}$. Cell lysates were prepared and assayed for luciferase activity. ${ }^{*} p<0.05$ vs. no tx.

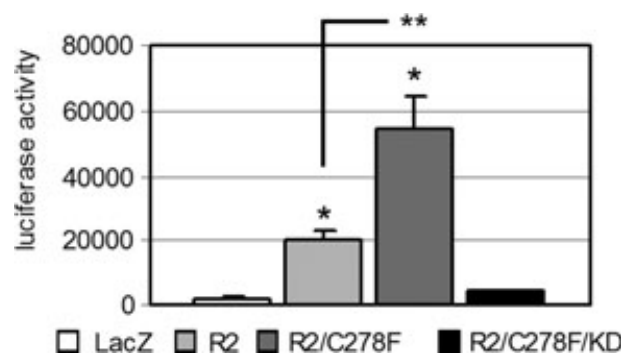

Fig. 4. Expression of Crouzon syndrome-associated fibroblast growth factor receptor, FGFR2 ${ }^{\mathrm{C} 278 \mathrm{~F}}$, induces $\mathrm{PC}-1$ promoter activity in undifferentiated, pre-osteoblastic MC3T3E1(C4) cells. MC3T3E1(C4) cells were co-transfected with PGL3/PC1-luc and a control vector expressing $\beta$-galactosidase (LacZ), wild type FGFR2 (R2), FGFR2 ${ }^{\mathrm{C} 278 \mathrm{~F}}$ (R2/C278F), or a kinase dead variant of FGFR2 ${ }^{\mathrm{C} 278 \mathrm{~F}}(\mathrm{R} 2 / \mathrm{C} 278 \mathrm{~F} / \mathrm{KD})$, washed and incubated for $24 \mathrm{~h}$. Cells were then treated with $50 \mathrm{ng} / \mathrm{ml}$ recombinant FGF2 for an additional $24 \mathrm{~h}$. Cell lysates were prepared and assayed for luciferase activity. ${ }^{*} p<0.05$ vs. no tx; ${ }^{* *} p<0.05$ vs. transfection with wild type FGFR2 (R2).

we have constructed a PC-1 gene promoter/Firefly luciferase gene reporter construct. Initial results indicate that this reporter construct is selectively responsive to FGF2. Treatment of undifferentiated, preosteoblastic MC3T3E1(C4) cells with FGF2 for $24 \mathrm{~h}$ elicits a significant increase in luciferase activity (indicative of PC-1 promoter activity), as compared with no treatment or treatment with BMP2 (Fig. 3). This result appears to be cell type specific, as similar experiments in the non-osteoblastic, COS7 cell line do not elicit activity of the PC-1 promoter (data not shown) (Fig. 4).

\section{Expression of Crouzon mutant FGFR2 induces PC-1 promoter activity in MC3T3E1(C4) cells}

Although treatment of cells with FGF2 and expression of craniosynostosis syndrome-associated mutant FGFRs theoretically induce FGF/FGFR signaling to a 
similar extent, it is possible that expression of mutant FGFRs will not induce PC-1 promoter activity. In order to establish that expression of a craniosynostosis syndrome-associated FGFR is itself adequate to stimulate PC-1 promoter activity, a Crouzon syndrome-associated $\mathrm{C} 278 \mathrm{~F}$ mutant form of FGFR2 was transfected into cells expressing the PC1-luciferase reporter construct. Results confirm that expression of Crouzon mutant FGFR2 ${ }^{\mathrm{C} 278 \mathrm{~F}}$ induces luciferase activity in these cells. Consistent with the hypothesis that induction of PC-1 promoter activity occurs downstream of signaling from the mutant receptor, a kinase-dead variant of this mutant receptor (FGFR2 ${ }^{\mathrm{C} 278 \mathrm{~F} / \mathrm{KD}}$ ) did not induce $\mathrm{PC}-1$ promoter activity (Fig. 3).

\section{Discussion}

The effects of FGF2 treatment on the expression of PC1, ANK and TNAP in MC3T3E1(C4) cells, a calvarial osteoblastic cell line, provide an important potential contributing mechanism for FGF2 effects upon mineralization. FGF2 treatment up-regulates PC-1 and ANK, which should increase levels of extracellular pyrophosphate. At the same time, FGF2 inhibits TNAP expression and activity, which would prevent the enzymatic hydrolysis of this pyrophosphate into phosphate. It appears that these three factors function together downstream of FGF2 to generate increased levels of extracellular pyrophosphate, providing an important potential contributory mechanism for the in vitro inhibition of FGF2 on mineralization (Fig. 1).

Utilizing a PC-1 gene promoter/firefly luciferase construct, here we confirm that FGF/FGFR signaling induces PC-1 expression in osteoblastic cells in culture. PC-1 promoter activity is not induced in the non-osteoblastic, COS7 cell line upon FGF2 treatment, suggesting that this is an osteoblastic cell type specific phenomena. Future experiments utilizing this PC-1 promoter/ reporter construct should allow us to investigate the mechanism by which FGF/FGFR signaling specifically induces expression of PC-1 in osteoblastic cells, through a process of systematic promoter analysis and chromatin immunoprecipitation DNA binding protein assays.

Importantly, at the clinical level, these findings may also provide new insights into the mechanism of the FGFR-associated craniosynostosis syndromes. Although craniosynostosis syndromes have been traditionally described as diseases of increased bone mineralization, this may not be the most accurate description of these syndromes. A comprehensive survey of 61 patients with Crouzon Syndrome by Kreiborg in 1981 revealed that a high percentage of patients exhibit conductive hearing loss, joint stiffness, calcification of the stylohyoid ligament and vertebral fusions (28). These are all signs of pathologic, excessive calcification of normally non-mineralized tissues. More recent studies involving mouse models of mutant FGFR-associated craniosynostosis syndromes also suggest that the craniosynostosis syndrome phenotype may not be that of excessive bone mineralization. Mice transgenic for an Apert syndrome-associated mutant FGFR2 show evidence of diminished bone formation. Vital bone staining of cranial bones from these mutant mice showed significantly decreased cranial bone thickness compared to wild type mice, despite the fact that cranial suture fusion was evident (29). In a separate study, mice transgenic for a Crouzon syndromeassociated mutant FGFR2 showed similar overall bone densities and diminished vertebral body ossification compared to wild type counterparts. Strikingly, the mice transgenic for Crouzon syndrome mutant FGFR2 also exhibited multiple vertebral fusions and synarthrosis of multiple joints (30). Taken together, these findings suggest that syndromic craniosynostosis does not result from excessive bone mineralization. Perhaps it would be more accurate to describe the FGFR linked craniosynostosis syndromes as diseases of excessive calcification of normally non-mineralized tissues. If this is the case, it is critical to recognize that increased levels of extracellular pyrophosphate can result in pathologic calcification, as has been evidenced in human diseases involving excessive ANK or PC-1 activity $(14,31,32)$. Our results suggest the possibility that craniosynostotic mutant FGFR signaling leads to enhanced expression of PC-1 in pre-osteoblastic cells. This in turn would yield a phenotype of excessive extracellular pyrophosphate with the potential for calcification of typically non-mineralized tissues, including the young cranial suture.

\section{References}

1. De Moerlooze L, Dickson C. Skeletal disorders associated with fibroblast growth factor receptor mutations. Curr Opin Genet Dev 1997;7:378-85. 
2. Ornitz DM, Marie PJ. FGF Signaling in endochondral and intramembranous bone development and human genetic disease. Genes Dev 2002;16:1446-65.

3. Marie PJ. Fibroblast growth factor signaling controlling osteoblast differentiation. Gene 2003;316:23-32.

4. DePollack C, Renier D, Hott M, Marie P. Increased bone formation and osteoblastic cell phenotype in premature cranial suture ossification (craniosynostosis). J Bone Min Res 1996;11:401-7.

5. Lomri A, Lemonnier J, Hott M, Perseval N, Lajeunie E, Munnich A et al. Increased calvaria cell differentiation and bone matrix formation induced by fibroblast growth factor receptor 2 mutations in Apert syndrome. J Clin Investig 1998;101:1310-7.

6. Fragale A, Tartaglia M, Bernardini S, Michela de Stasio AM, di Rocco C, Velardi F et al. Decreased proliferation and altered differentiation in osteoblasts from genetically and clinically distinct craniosynostotic disorders. Am J Path 1999;154:1465-77.

7. Rice D, Kim H, Thesleff I. Apoptosis in murine calvarial bone and suture development. Eur J Oral Sci 1999;107:265-75.

8. Dry GM, Yasinskaya YI, Williams JK, Ehrlich GD, Preston RA, Hu FZ et al. Inhibition of apoptosis: a potential mechanism for syndromic craniosynostosis. Plas Reconstr Surg 1999;107:425-32.

9. Lemmonier J, Delannoy P, Hott M, Lomri A, Modrowski D, Marie PJ. The Ser252Trp fibroblast growth factor receptor-2 (FGFR-2) mutation induces PKC-independent downregulation of FGFR-2 associated with premature calvaria osteoblast differentiation. Exp Cell Res 2002;256:158-67.

10. Lemonnier J, Hay E, Delannoy P, Fromigue O, Lomri A, Modrowski D et al. Increased osteoblast apoptosis in Apert craniosynostosis: role of protein kinase $\mathrm{C}$ and interleukin-1. Am J Path 2001;158:1833-42.

11. Mansukhani A, Bellosta P, Sahni M, Basilico C. Signaling by fibroblast growth factors (FGF) and fibroblast growth factor receptor 2 (FGFR2)-activating mutations blocks mineralization and induces apoptosis in osteoblasts. J Cell Bio 2000;149: 1297-308.

12. Register TC, Wuthier RE. The effect of pyrophosphate and two diphosphonates on ${ }^{45} \mathrm{Ca}$ and ${ }^{32} \mathrm{Pi}$ uptake and mineralization by matrix vesicle-enriched fractions and by hydroxyapatite. Bone 1985;6:307-12.

13. Anderson HC, Sipe JB, Hessle L, Dhamyamraju R. Atti E. Camacho NP et al. Impaired calcification around matrix vesicles of growth plate and bone in alkaline phosphatase-deficient mice. Am J Path 2004;164:841-7.

14. Terkeltaub R, Rosenbach M, Fong F, Goding J. Causal link between nucleotide pyrophosphohydrolase over activity and increased intracellular inorganic pyrophosphate generation demonstrated by transfection of cultured fibroblasts and osteoblasts with plasma cell membrane glyoprotein-1. Arthrit Rheum 1994;37:934-41.

15. Fleisch H, Straumann F, Schenk R, Bisaz S, Allgower M. Effect of condensed phosphates on calcification of chick embryo femurs in tissue culture. Am J Physiol 1966;211:821-5.

16. Johnson K, Moffa A, Chen Y, Prizker K, Goding J, Terkeltaub R. Matrix vesicle plasma cell membrane glycoprotein-1 regulates mineralization by murine osteoblastic MC3T3 cells. J Bone Min Res 1999;14:883-92.

17. Johnson KA, Hessle L, Vaingankar S, Wennerg C, Mauro S, Narisawa $\mathrm{S}$ et al. Osteoblast tissue-nonspecific alkaline phosphatase antagonizs and regulates PC-1. Am J Physiol Int Comp Physiol 2000;279:1365-77.

18. Johnson K, Goding J, Van Etten D, Sali A, Hu S, Farley D et al. Linked deficiencies in extracellular PPi and osteopontin mediate pathologic calcification associated with defective PC-1 and ANK expression. J Bone Min Res 2003;18:994-1004.

19. Hessle L, Johnson KA, Anderson HC, Narisawa S, Sali A, Goding JW et al. Tissue-nonspecific alkaline phosphatase and plasma cell membrane glycoprotein-1 are central antagonistic regulators of bone mineralization. Proc Nat Acad Sci 2002;99:9445-9.

20. Pendleton A, Johnson MD, Hughes A, Gurley KA, Ho AM, Doherty $\mathrm{M}$ et al. Mutations in ANKH cause chondrocalcinosis. Am J Hum Gen 2002;71:933-40.

21. Reichenberger E, Tiziani V, Watanabe S, Park L, Ueki Y, Santanne $\mathrm{C}$ et al. Autosomal dominant craniometaphyseal dysplasia is caused by mutations in the transmembrane protein ANK. Am J Hum Gen 2001;68:1321-6.

22. Nurnberg P, Thiele H, Chandler D, Hohne W, Cunningham ML, Ritter $\mathrm{H}$ et al. Heterozygous mutations in ANKH, the human ortholog of the mouse progressive ankylosis gene, result in craniometaphyseal dysplasia. Nat Gen 2001;28:37-41.

23. Ho AM, Johnson MD, Kingsley DM. Role of the mouse ank gene in control of tissue calcification and arthritis. Science 2000;289: 265-70.

24. Sohn P, Crowley M, Slattery E, Serra R. Developmental and TGF- $\beta$ mediated regulation of Ank mRNA expression in cartilage and bone. Osteoarthr Cart 2002;10:482-90.

25. Hatch NE, Nociti F, Swanson E, Bothwell M, Somerman M. FGF2 alters expression of the pyrophosphate/phosphate regulating proteins, PC-1, ANK, TNAP, in the calvarial osteoblastic cell line, MC3T3E1(C4). Conn Tiss Res 2005;46:184-92.

26. Sudo H, Kodama H, Amagai Y, Yamamoto S, Kasai S. In vitro differentiation and calcification in a new clonal osteogenic cell line derived from newborn mouse calvaria. J Cell Bio 1983;96: 191-8.

27. Wang D, Christensen K, Chawla K, Xiao G, Krebsbach P, Franceschi R. Isolation and characterization of MC3T3-E1 preosteoblast subclones with distinct in vitro and in vivo differentiation/mineralization potential. J Bone Min Res 1999;14:893-903.

28. Kreiborg S. Crouzon syndrome: a clinical and roentgencephalometric study. Scan J Plast Reconstr Surg, 1981;18 (Suppl.):1-198.

29. Chen L, Li D, Li C, Engel A, Deng CX. A Ser250Trp substitution in mouse fibroblast growth factor receptor 2 (Fgfr2) results in craniosynostosis. Bone 2003;33:169-78.

30. Eswarakumar VP, Horowitz MC, Locklin R, Morriss-Kay GM, Lonai P. A gain of function mutation of Fgfr2c demonstrates the roles of this receptor variant in osteogenesis. Proc Nat Acad Sci 2004;101:12555-60.

31. Johnson K, Hashimoto S, Lotz M, Pritzker K, Goding J, Terkeltaub R. Up-regulated expression of the phosphodiesterase nucleotide pyrophosphatase family member PC-1 is a marker and pathgenic factor for knee meniscal cartilage matrix calcification. Arthritis Rheum 2001;44:1071-81.

32. Johnson K, Terkeltaub R. Upregulated ank expression in osteoarthritis can promote both chondrocyte MMP-13 expression and calcification via chondrocyte extracellular PPi excess. Osteoarthr Cart 2004;12:321-35. 